
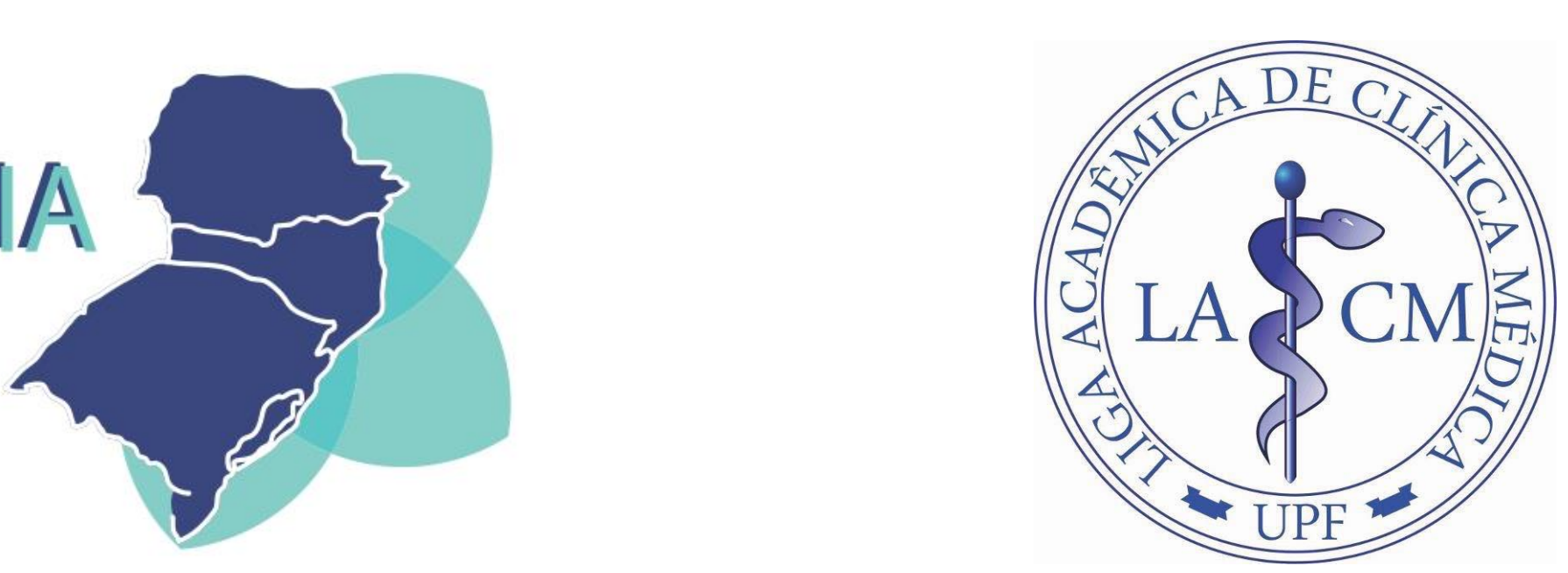

\title{
SÍNDROME DE RAMSAY HUNT E LUPUS ERITEMATOSO SISTÊMICO: UM RELATO DE CASO
}

Ana Claudia Kurmann ${ }^{1}$, Agnes Gabrielle Wagner ${ }^{1}$, Augusto Poloniato Gelain ${ }^{1}$, Gabriel de Carvalho Scortegagna ${ }^{1}$, Gabriela Gregory ${ }^{1}$, Jéssica Maldaner Lui ${ }^{1}$, João Vitor Dal Bosco Zaffari ${ }^{1}$, Luiza Mattos Volpi ${ }^{1}$, Mariana Mesko da Fonseca Lubbe ${ }^{1}$, Martina Souilljee Birck ${ }^{1}$, Nicolle Surkamp ${ }^{1}$, Thamyze Mânica Martio ${ }^{1}$,Victor Antônio Kuiava ${ }^{1}$, César Augusto Caleffi Paiva ${ }^{2}$, Fabiana Piovesan ${ }^{3}$

${ }^{1}$ Acadêmicos de Medicina da Universidade de Passo Fundo (UPF) ${ }^{2}$ Médico Reumatologista e Professor de Reumatologia da Universidade de Passo Fundo (UPF) ${ }^{3}$ Médica Nefrologista e Professora de Nefrologia da Universidade de Passo Fundo (UPF)

\section{INTRODUÇÃO}

A Síndrome de Ramsay Hunt (SRH), ou Herpes Zoster Ótico (HZO), é uma rara complicação do vírus Varicela Zoster (VVZ), o qual acomete o gânglio geniculado do nervo facial $^{1,2}$. A incidência é de cinco em cada cem mil habitantes, sendo mais comum na faixa etária entre 20-30 anos e no sexo feminino ${ }^{2,3}$. Os principais sintomas são dor na orelha, paralisia periférica facial e lesões herpetiformes ${ }^{3,4}$. A literatura descreve ainda sinais e sintomas neurológicos como zumbidos, vertigem, distúrbios auditivos, nistagmo, náuseas e vômitos ${ }^{1,4,5}$. O diagnóstico é clínico e o tratamento deve ser o uso combinado de corticoides e aciclovir ${ }^{2,4}$.

\section{OBJETIVOS}

$\mathrm{O}$ presente relato visa discutir o caso de paciente que desenvolveu a SRH, estando imunossuprimida em decorrência do tratamento para Lúpus Eritematoso Sistêmico (LES).

\section{RELATO DO CASO}

Paciente feminina, 21 anos, apresentou quadro de herpes zoster com paralisia periférica do nervo facial à direita, otite e mastoidite, sendo tratada com ceftriaxona e aciclovir. Após 15 dias, fez quadro de febre, intenso prurido auricular e periauricular à direita, hipoacusia, náuseas e vômitos. Ao exame físico possuía eritema, edema auricular, úlceras, lesões descamativas e paralisia facial à direita, quadro compatível com a SRH. Diagnosticada com LES há 3 anos, desenvolveu há 6 meses quadro grave de nefrite lúpica, estando imunossuprimida desde então com o uso de corticoides em altas doses e micofenolato mofetil.

\section{DISCUSSÃO}

A SRH é uma rara complicação da reativação do VVZ no gânglio geniculado, que causa inflamação, edema e a consequente compressão do VII par de nervos cranianos e é responsável por $12 \%$ dos casos de paralisia periférica do nervo facial ${ }^{2,3}$.
A presença de sinais clínicos como náuseas e vômitos está sempre relacionada à danos vestibulares ${ }^{4}$. No presente relato, a paciente encontrava-se em terapia imunossupressora devido a quadro grave de nefrite lúpica: sabe-se que pacientes imunocomprometidos são mais suscetíveis a essa condição ${ }^{6}$. O diagnóstico e o início da terapia devem ser precoces a fim de evitar sequelas, uma vez que os danos neurológicos estão relacionados a gravidade dos sintomas inciais ${ }^{3,4}$.

\section{CONCLUSÃO}

A SRH é a presença de $\mathrm{HZO}$ associada à paralisia periférica do nervo facial. Envolve desde a presença de lesões herpetiformes até sinais de comprometimento neurológico e é uma condição mais comum em imunocomprometidos. O diagnóstico é clínico e o tratamento precoce deve ser realizado com corticoides e antivirais a fim de evitar sequelas.

\section{REFERENCIAS}

1. Hunt JR. On herpetic inflammations of the geniculate ganglion: a new syndrome and its complications. J Nerv Ment Dis 1907; 34: 73-96

2. Youghoon J, Heryim L. Ramsay Hunt syndrome. J Dent Anesth Pain Med 2018; 18(6):333-337

3. Monsanto RC, et al. Treatment and Prognosis of Facial Palsy on Ramsay Hunt Syndrome: Results Based on a Review of the Literature. Int Arch Otorhinolaryngol 2016; 20:394-400.

4. Wagner G, Klinge H, Sachse MM. Ramsay Hunt syndrome. JDDG. 2012; 10:238-243

5. Sweeney CJ, Gilden DH. Ramsay Hunt syndrome. J Neurol Neurosurg Psychiatry 2001; 71:149-154

6. Gondivkar S, Parikh V, Parikh R. Herpes zoster oticus: a rare clinical entity. Contemp Clin Dent. 2010; $1(2): 127-9$ 